\title{
Relato de profissionais do Atendimento Educacional Especializado em uma formação sobre Paralisia Cerebral
}

\author{
Report of professionals of Educational Care Specialized in a trainning on \\ Cerebral Palsy
}

\section{Relato de profesionales del Atendimiento Educacional Especializado en una formación sobre Parálisis Cerebral}

\section{Juliana Fonsêca de Queiroz Marcelino}

Professora doutora da Universidade Federal de Pernambuco, Recife, PE, Brasil

E-mail: juliana.marcelino@ufpe.br ORCID: https://orcid.org/0000-0003-2961-3292

Marília de Arruda dos Santos

Graduada pela Universidade Federal de Pernambuco, Recife, PE, Brasil

E-mail: maarilia-maia@hotmail.com ORCID: https://orcid.org/0000-0003-3380-3478

\section{Lauriceia Tomaz da Silva Gomes}

Mestra pela Universidade Federal da Paraíba, João Pessoa, PE, Brasil

E-mail: lauriceiatomaz@hotmail.com ORCID: https://orcid.org/0000-0002-3080-3176

\section{Lucas de Paiva Silva}

Graduado pela Universidade Federal de Pernambuco, Recife, PE, Brasil

E-mail: lucaspaiva.to@gmail.com ORCID: https://orcid.org/0000-0003-4258-6591

\section{Laura Bezerra Martins}

Professora doutora da Universidade Federal de Pernambuco, Recife, PE, Brasil

E-mail: bmartins.laura@gmail.com ORCID: https://orcid.org/0000-0003-0578-7271

Recebido em 20 de favereiro de 2020

Aprovado em 28 de maio de 2021

Publicado em 21 de junho de 2021

\section{RESUMO}

Com o aumento da demanda de alunos com deficiência na Rede Escolar Pública, houve a criação do Atendimento Educacional Especializado (AEE), cuja formação é primordial para a efetivação da inclusão. O objetivo da pesquisa foi analisar o perfil dos profissionais do AEE da Rede Municipal do Recife, bem como seus relatos e necessidades no processo de inclusão de estudantes com Paralisia cerebral (PC). O estudo descritivo, transversal e quanti-qualitativo foi realizado no Centro de Formação de Educadores Professor Paulo Freire, no período de setembro a outubro de 2016, com 144 profissionais do AEE, que participaram de uma formação mediada pelos pesquisadores sobre PC. Foi utilizado um questionário semiestruturado para caracterização profissional dos participantes, além do diário de campo e gravador de áudio, para registro dos discursos. Como resultados, encontrou-se que a maioria dos participantes possui graduação em pedagogia e pósgraduação em educação especial, e trabalham como AEE há cerca de 4 a 10 anos. Os temas que emergiram nos discursos dos participantes foram: causa e quadro clínico da PC; como lidar com a criança com disfunções por PC; diferenças entre PC e outras patologias; 
http://dx.doi.org/10.5902/1984686X42569

demandas dos AEE para atender a este público. Os resultados indicaram 0 desconhecimento e a insegurança dos profissionais do AEE em lidar com esta população, o que aponta para a necessidade de realização de parcerias entre a saúde e a educação na política de formação, indispensável para a inclusão escolar e qualidade de vida dos alunos com deficiência e dos educadores.

Palavras-chave: Educação Especial; Equipamentos para Educação Especial; Paralisia Cerebral.

\section{ABSTRACT}

With the increase in the demand of students in the Public Network, there was a creation of the Specialized Educational Assistance (SEA), which was essential for the accomplishment of inclusion. The objective of the research was to analyze the profile of the professionals of the SEA of Recife Municipal Network, as well as their reports and needs in the process of inclusion of students with Cerebral Palsy (PC). The descriptive, cross-sectional and quantitative-qualitative study was carried out at the Professor Paulo Freire Teacher Training Center, in September 2016, with 144 SEA professionals, who participated in a training of the researchers on the PC. A semi-structured questionnaire was used for professional characterization of the participants, in addition to the field diary and audio recorder, to record speeches. As it turned out, most of the students appear in post-graduate education and have worked as SEAs for about 4 to 10 years. The themes that emerged in the speeches were: cause and clinical picture of the PC; How to deal with a child with PC dysfunction; differences between PC and other pathologies; demands of SEAs to serve this public. The results indicate the lack of knowledge and insecurity of SEA professionals in dealing with the population, which means that it is necessary to carry out health education and education in politics, which is indispensable for school inclusion and the quality of life of students with disabilities and educators.

Keywords: Cerebral palsy; Special education; Special education equipment.

\section{RESUMEN}

Con la creciente demanda de estudiantes con discapacidades en la Red de Escuelas Públicas, se creó la Atención Educativa Especializada (AEE), cuya formación es esencial para la inclusión. El objetivo de esta investigación fue analizar el perfil de los profesionales de la ESA de la Red Municipal de Recife, así como sus informes y necesidades en el proceso de inclusión de estudiantes con parálisis cerebral (PC). El estudio descriptivo, transversal y cualitativo se realizó en el Centro de Formación de Educadores del Profesor Paulo Freire, de septiembre a octubre de 2016, con 144 profesionales de la AEE, que participaron en una formación mediada por investigadores en CP. Se utilizó un cuestionario semiestructurado para la caracterización profesional de los participantes, así como el diario de campo y la grabadora de audio para grabar los discursos. Como resultado, se descubrió que la mayoría de los participantes tienen un título en pedagogía y educación especial de posgrado, y trabajan como ESA durante aproximadamente 4 a 10 años. Los temas que surgieron en los discursos de los participantes fueron: causa y cuadro clínico de la PC; cómo lidiar con niños con disfunción CP; diferencias entre CP y otras patologías; demandas 
de las ESA para cumplir con este público. Los resultados indicaron la falta de conocimiento y la inseguridad de los profesionales de la ESA al tratar con esta población, lo que señala la necesidad de alianzas entre la salud y la educación en la política de capacitación, indispensable para la inclusión escolar y la calidad de vida de los estudiantes con discapacidad y educadores.

Palabras clave: Educación especial; Equipo de educación especial; Parálisis cerebral.

\section{Introdução}

O Brasil passou a ser um dos primeiros países da América Latina a apresentar em sua legislação, políticas de educação que atendam a todos e a elaborar documentos norteadores para a prática nacional do atendimento a pessoas com deficiência no sistema regular de ensino. Desde 1988, foi estabelecido o direito de pessoas com deficiência a receberem educação de preferência em escolas com ensino regular (BRASIL, 2016).

Em paralelo aos movimentos que aconteciam no Brasil, emerge uma conferência com representantes de diversos países, culminando na Declaração de Salamanca, em 1994. Este documento trouxe uma estimulante e desafiadora concepção de Educação Especial ao utilizar o termo "pessoa com necessidades educacionais especiais", abrangendo todas as crianças ou jovens que possuíam necessidades decorrentes de suas características de aprendizagem, independentemente de ter uma deficiência física, mental ou estar em um contexto social, que dificultasse seu aprendizado (BRASIL, 1996).

No Brasil, mais recentemente, a Lei de oㅜ 13.146 (BRASIL, 2015), no Art. 28, cita que incumbe ao poder público aprimorar os sistemas educacionais, visando garantir as condições de acesso, permanência, participação e aprendizagem, além de garantir o atendimento educacional especializado, assim como os demais serviços e adaptações razoáveis com vistas à educação inclusiva. O documento supracitado afirma que, em todos os níveis e modalidades, ao longo de toda a vida, o processo de aprendizagem deve ser garantido. Além disso, que $\mathrm{o}$ atendimento educacional especializado deve ser institucionalizado por meio do projeto pedagógico, assim como os demais serviços e adaptações necessárias, com medidas individualizadas e coletivas ambientais, para atender às especificidades dos estudantes com deficiência e garantir o seu pleno acesso ao currículo em condições de igualdade, promovendo a conquista e o exercício de sua autonomia.

Sabe-se que o professor possui um papel de relevância no contexto escolar, uma vez que está em ligação direta com a criança, constituindo-se como meio de transmissão do 
http://dx.doi.org/10.5902/1984686X42569

conhecimento, além de ser o facilitador no processo de ensino-aprendizagem. Considerase também que a formação do professor pode influenciar, de diferentes maneiras, sua atuação na sala de aula. Essa formação será a base de seu desempenho e a preparação para situações que podem vir a surgir em seu cotidiano (TAVARES; SANTOS; FREITAS, 2016).

Dessa forma, após o aumento do quantitativo de alunos com deficiência nas escolas, para atender às necessidades da população, em 2009, a resolução № 04, de 2 de outubro de 2009 instituiu a criação do Atendimento Educacional Especializado (AEE). Este possui como função identificar, elaborar e organizar recursos pedagógicos e de acessibilidade que eliminem as barreiras arquitetônicas e atitudinais para a completa participação dos alunos, considerando suas necessidades específicas. As atividades desenvolvidas no atendimento educacional especializado são distintas das realizadas na sala de aula comum, não sendo substitutivas à escolarização. Esse atendimento complementa e/ou suplementa a formação dos alunos em relação à autonomia e independência na escola e fora dela (BRASIL, 2010).

Segundo a Secretaria de Educação do Recife (2014), o profissional do AEE que faz uso da sala de recursos multifuncionais deverá ter curso de graduação, pós-graduação e/ou formação continuada que o capacite para atuar na área de educação especial, objetivando ao atendimento das Necessidades Educacionais Especiais. Ele deve orientar os outros profissionais da unidade educacional, no que diz respeito a serviços e recursos necessários para a inclusão do estudante. Os profissionais que deverão ser orientados por esses profissionais são, além do professor de sala de aula do ensino regular, agente de apoio ao desenvolvimento escolar especial (AADEE), equipe gestora e equipe pedagógica (RECIFE, 2015).

Neste contexto, o profissional que realiza o AEE se depara com inúmeras necessidades educacionais especiais provenientes de uma gama bastante variada de patologias e disfunções. Dentre estas, encontra-se a paralisia cerebral (PC), um conjunto de desordens não progressivas do desenvolvimento neurológico, presente, em geral, no início da primeira infância e permanecendo até a idade adulta. Suas causas são diversas, incluindo genética, congênita, infecciosa e etiologias traumáticas, podendo ocorrer nos períodos pré-natal, perinatal ou pós-natal. O perfil das lesões cerebrais difere entre os pacientes em localização e extensão (DIAS et al., 2015).

A paralisia cerebral pode ser classificada quanto ao tipo motor em: espástica, discinética, atáxica e, em poucos casos, hipotônica. Já em relação à distribuição anatômica, 
http://dx.doi.org/10.5902/1984686X42569

em hemiplegia, que se caracteriza pelo comprometimento de um dos lados do corpo; diplegia, no qual ambos os lados são afetados, porém, há maior comprometimento de membros inferiores do que superiores; quadriplegia ou tetraplegia, com a presença de espasticidade nos quatro membros a sequela sobre os membros superiores é igual aos inferiores. Em casos raros, um membro é poupado e este é referido como triplegia (MORGAN et al., 2015).

Tais alterações, na maioria das vezes, podem provocar padrões específicos de postura e de movimentos que podem afetar a funcionalidade dessas crianças, ou seja, a PC pode interferir de maneira significativa na interação da criança em contextos primordiais, como o escolar (MANCINI et al., 2004).

Diversos profissionais da área de saúde podem contribuir para o processo de inclusão escolar para usuários com sequelas da PC, dentre eles o terapeuta ocupacional e o fisioterapeuta que, neste contexto, têm os objetivos de prescrever recursos de tecnologia assistiva, realizar adequação postural do estudante e orientar aos professores, para facilitar o desempenho funcional dos estudantes nas tarefas escolares (PERAZZO, 2015).

A utilização de recursos tecnológicos e de acessibilidade é necessária para o processo de inclusão de um grande número de crianças com deficiência. Tais recursos objetivam facilitar o atendimento às demandas do ambiente, para que esses alunos consigam frequentar as aulas, atuar com um desempenho adequado e com autonomia no contexto escolar, em consonância com os princípios de cidadania (MARINS; EMMEL, 2011).

Diante dos desafios do processo de inclusão escolar de crianças com sequela de paralisia cerebral na rede regular de ensino, que precisam ser enfrentados pelos educadores, no intuito de conhecer esta realidade, este estudo propõe analisar o perfil dos profissionais do AEE da Rede Municipal do Recife, bem como seus relatos e necessidades no processo de inclusão de estudantes com sequela de Paralisia cerebral (PC).

\section{Método}

Trata-se de um estudo que possui desenho descritivo, transversal e quanti-qualitativo. Após a autorização da Secretaria Municipal de Educação, foi realizada uma formação no Centro de Formação de Educadores Professor Paulo Freire por uma profissional e duas acadêmicas de Terapia Ocupacional, durante um projeto de extensão da Universidade Federal de Pernambuco. Os dados foram coletados no período de setembro a outubro de 
http://dx.doi.org/10.5902/1984686X42569

2016, com 144 profissionais da educação que trabalham no AEE da Rede Municipal do Recife, que participaram da formação desenvolvida nesta pesquisa e entregaram 0 questionário respondido.

Este questionário, semiestruturado, foi utilizado para a coleta de dados com a finalidade de caracterizar os profissionais do AEE. Também foram utilizados como instrumentos o diário de campo, para registrar em tempo real, conversas, comentários e perguntas durante a formação, relacionados com o tema abordado; também gravados em áudio. Realizaram-se 11 encontros com 144 profissionais do AEE da Região Metropolitana do Recife, divididos em grupos pela Divisão de Educação Especial. Cada profissional participou apenas de um grupo com duração de 3 horas, em média, onde foi ministrada, pelo pesquisador, uma exposição dialogada no tema Paralisia Cerebral. Os participantes eram instigados a discutir o assunto abordado, sendo-lhes oferecida a oportunidade de realizarem perguntas e comentários. A exposição dialogada consiste em uma troca de diálogos, compreendida da seguinte forma:

Sendo o diálogo uma relação eu-tu, é necessariamente uma relação de dois sujeitos. Toda vez que se converta o "tu" desta relação em mero objeto, se terá pervertido o diálogo e já não se estará educando, mas deformando. Este esforço sério de capacitação deverá estar acompanhado permanentemente de um outro: o da supervisão, também dialogal, com que se evitam os perigos da tentação do antidiálogo (FREIRE, 1967, p.114).

Em relação à exposição sobre a Paralisia Cerebral, discorreu-se sobre seu conceito, etiologia, características clínicas e funcionais, instrumentos de classificação motora, bem como terapias, procedimentos médicos e recursos presentes na rotina destas crianças. Foram utilizados vídeos para auxiliar a compreensão sobre as caraterísticas dos quadros da PC.

Após a exposição dialogada dos conteúdos, foi aplicado o questionário semiestruturado, contendo questões sobre: identificação do professor, tempo que trabalha com AEE, formação, quantidade de crianças com sequela de PC atendidas, além de um espaço para complementar ou acrescentar informações, entre outras. Após o recolhimento dos questionários, seus dados foram transcritos no Google Docs. Os dados coletados no diário de campo e nas gravações em áudio foram transcritos e lidos. O conteúdo extraído destes dados foi submetido à codificação, categorização e interpretação, com base no método de análise de conteúdo. Este se refere a um conjunto de técnicas de análise das comunicações visando obter, por procedimentos sistemáticos e objetivos de descrição do 
http://dx.doi.org/10.5902/1984686X42569

conteúdo das mensagens, as inferências do conteúdo da comunicação de um texto replicavam ao seu contexto social (CAREGNATO; MUTTI, 2006).

Após as transcrições das gravações de áudio e análise do diário de campo, foram confirmadas as seguintes categorias temáticas: "etiologia", "quadro clínico da paralisia cerebral", "como lidar com a criança com sequela de PC", e "outras patologias", depois, analisados qualitativamente. A partir dos textos ainda foram identificadas demandas dos participantes, que serão apresentadas em forma de quadro. Os dados do questionário referentes ao perfil profissional foram quantificados a fim de caracterizar o perfil profissional.

É válido ainda ressaltar que os participantes foram enumerados como P1, P2..., com o objetivo de preservar suas identidades. $O$ trabalho foi submetido e aprovado no Comitê de Ética em Pesquisa Envolvendo Seres Humanos do Centro de Ciências da Saúde da UFPE sob CAAE 55342916.2.0000.5208.

\section{Resultados e discussão}

Para facilitar a compreensão, os resultados serão apresentados em 6 seções. A primeira seção descreve o perfil dos profissionais participantes, e as seguintes serão divididas conforme as categorias encontradas, já mencionadas na metodologia deste trabalho.

\section{Caracterização dos profissionais}

Foram capacitados 144 profissionais que realizam o AEE. Destes, 70 possuem graduação em pedagogia e 21 em psicologia, os demais são graduados em ciências biológicas (4), serviço social (3), letras (8), fonoaudiologia (3), ciências sociais (1), comunicação social (1), geografia (1), educação física (1), secretariado (1), 14 possuem graduação sem especificação do curso, e 16 responderam outros. Em relação à pósgraduação, apenas 9 possuem uma pós graduação, os demais possuem mais de uma, distribuídas da seguinte forma: 84 em educação especial/educação inclusiva, 38 em psicopedagogia, 4 mestrados (sendo 1 mestre em educação) e 3 possuem doutorado (sendo 1 doutor em educação). Os demais possuem a pós-graduação em áreas como tecnologia na educação, administração escolar, neuropsicologia, alfabetização, e 16 responderam outros. Acerca do tempo de atuação no AEE, 15 trabalham há menos de 1 ano, 36 de 1 a 3 anos, 59 trabalham de 4 a 10 anos, e 34 acima de 10 anos. 
http://dx.doi.org/10.5902/1984686X42569

Com relação à localização das escolas onde o AEE é realizado, o gráfico 1 expõe a distribuição de participantes por Região Político Administrativa.

Gráfico 1 - Distribuição dos participantes por Região Político Administrativa (RPA) em Recife, 2017

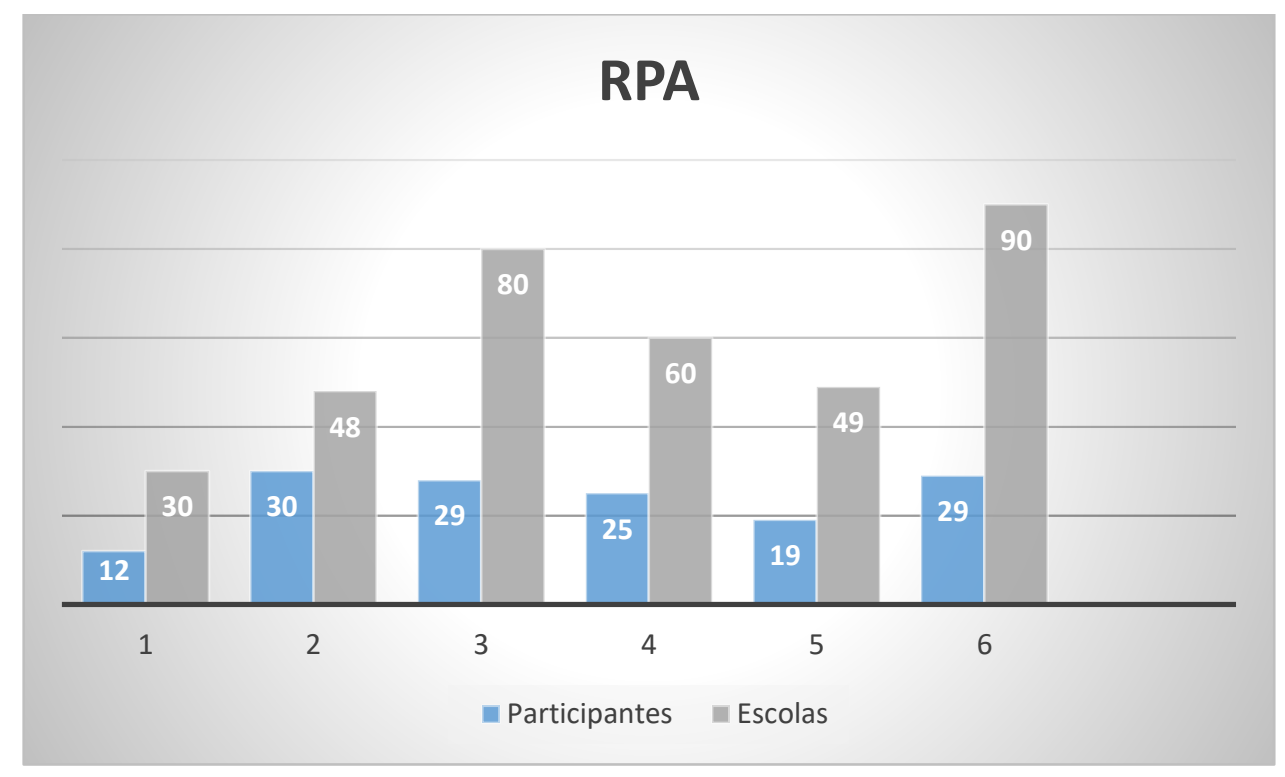

Fonte: Elaboração dos autores (2020).

\section{Etiologia}

No momento em que foi perguntado, aos participantes, o que eles entendiam sobre $\mathrm{PC}$, percebeu-se que nem todos os participantes responderam à pergunta. Contudo, alguns respondentes deram declarações do que entendiam, conforme pode ser observado abaixo:

Eu acho que é uma disfunção neuronal. (P1)

Acontece em um acidente, falta oxigênio no cérebro geralmente, que estar no feto ainda ou por algum acidente pós-nascimento. (P2)

Pelos discursos apresentados acima, mesmo com incerteza percebe-se que existe uma noção sobre o que é Paralisia Cerebral. A PC representa uma sequela de caráter não progressivo, que acomete o sistema nervoso central imaturo e em desenvolvimento, acarretando alterações de déficits posturais, tônicos e na execução dos movimentos. A definição de PC mais recente preconiza que as alterações do desenvolvimento motor, advindas da lesão cerebral primária, consistem em aspectos permanentes e mutáveis, causando alterações musculoesqueléticas secundárias e limitações nas atividades (CHAGAS et al., 2008).

Em determinado momento quando a ministrante da palestra explicou sobre o tipo de paralisia cerebral que pode ser causada a partir da icterícia, houve o seguinte comentário: 
http://dx.doi.org/10.5902/1984686X42569

Meu filho teve (icterícia) eu recebi muita orientação "dê chá de alpiste, coloque um coco amarelo dentro do berço", e muita gente às vezes acreditam mais nesses métodos do que na orientação médica. (P7)

O discurso apresenta conceitos relacionados à medicina popular, compreendida como "conhecimentos e práticas arraigados tanto à cultura indígena quanto aos valores trazidos por colonizadores", que foram introduzidos e respeitados no cotidiano da população. Seus resultados podem causar repercussões sociais importantes, fazendo com que as pessoas acreditem nestas práticas. Embora não sejam recomendadas, algumas práticas ainda continuam a fazer parte do cotidiano de mães, no cuidado de suas crianças, porque estão baseadas na vivência, experimentação e avaliação do sucesso de seu uso diante de problemas de saúde (LUCHESI; BERETTA; DUPAS, 2010).

No caso da Icterícia, a medicina popular é utilizada principalmente com plantas, entretanto os profissionais de saúde não recomendam visto que ela é consequente à hiperbilirrubinemia, definida como uma alta concentração de bilirrubina no plasma. Esta situação é apresentada pela maioria dos recém-nascidos (RN), consistindo na coloração amarelada da pele, escleróticas e mucosas, pelo depósito de bilirrubina nestes locais (LUCHESI; BERETTA; DUPAS, 2010). Muitas vezes, os relatos que apresentam crenças populares trazem embutido um desconhecimento da situação, não apenas pela crença, mas pela fragilidade na argumentação quando se compreende fisiologicamente a causa da PC.

\section{Quadro clínico da paralisia cerebral}

Em relação ao momento em que a ministrante explicou sobre as características do quadro da Paralisia Cerebral houve os seguintes comentários e dúvidas:

Existe cirurgia para diminuir esses movimentos involuntários? Por que eu fiz um curso já há muitos anos em Brasília e um dos palestrantes que tinha PC, ele tinha feito uma cirurgia de diminuir os movimentos involuntários. (P10)

O discurso apresentado traz um tipo de abordagem ainda não conhecida na literatura. Segundo as Diretrizes de Atenção à Pessoa com Paralisia Cerebral (BRASIL, 2013), o tipo de paralisia cerebral discinética se caracteriza pela presença de movimentos irregulares mais evidentes quando o paciente inicia um movimento voluntário produzindo movimentos e posturas atípicos; engloba a distonia (tônus muscular muito variável desencadeado pelo movimento) e a coreoatetose (tônus instável, com a presença de movimentos involuntários 
http://dx.doi.org/10.5902/1984686X42569

e movimentação associada). O tratamento da coreoatetose é medicamentoso e não cirúrgico.

\begin{abstract}
Eu tinha um aluno com PC, que ele tinha todo um enrijecimento dos músculos e em alguns períodos, a mãe que era pediatra levava ele para São Paulo para aplicar acho que Botox. Ele voltava mais relaxado, e assim na época eu via na pratica. Quando acontecia essas coisas era quando ele ia para o chão, brincava na areia, a gente via que ele se beneficiava demais. (P12)
\end{abstract}

A participante acima relata um tipo de tratamento que produz bons resultados em relação à paralisia cerebral, percebe-se que a profissional é ciente desses benefícios.

Uma vez que o tratamento com toxina botulínica é favorável dentro do programa reabilitacional na qual a criança com paralisia cerebral terá um período de 3-4 meses de relaxamento induzido devido ao medicamento. Esta oportunidade deve ser aproveitada ao máximo, no intuito de maximizar os efeitos da toxina botulínica, e para isto os programas de fisioterapia e terapia ocupacional devem ser mais intensos neste período. A diminuição da espasticidade após a injeção de toxina botulínica associada à terapia física cria a possibilidade da aquisição de novos padrões funcionais; além disto, as mudanças biomecânicas provocadas nas funções musculares pela toxina botulínica melhoram as condições de fortalecimento e alongamento, e isto gera a oportunidade de fortalecimento dos músculos antagonistas aos injetados e assim restaura o equilíbrio entre eles (SPOSITO, 2010).

Eu não sabia nada até você começar a falar; eu acho que é mais fácil atender PC do que Paralisia Infantil. (P16)

Eu pensei que era sinônimo Paralisia Infantil e PC. (P17)

No comentário acima, observa-se o quanto é necessário capacitar esses profissionais, pois muitas vezes os mesmos não sabem como lidar com os alunos com deficiência. Este é um fator prejudicial na educação inclusiva, pois ausência de conhecimento, preparo e formação dos profissionais da educação contribuem para o reforço da exclusão (ALVES; TEBET, 2009). Além disso, o que compreendem sobre paralisia cerebral, na maioria das vezes, pertence ao campo do senso comum. Esse saber, resultado de um discurso socialmente produzido, costuma repercutir na estigmatização e rotulação dos aprendizes. Muitos equívocos são feitos quanto aos diagnósticos. O mais comum delas é atribuir à criança com paralisia cerebral, com comprometimentos motores severos e comprometimentos de fala, por exemplo, a incapacidade cognitiva (FRANCO; GUERRA, 2015). 
http://dx.doi.org/10.5902/1984686X42569

$\mathrm{Na}$ escola tem uma com esse problema, e tem uma listinha de coisas que ela não pode comer, tipo cuscuz. (P11)

A minha não pode tomar água e o leitinho dela tem que ser engrossado. (P12)

Nos discursos acima, que surgiram após a explicação do risco de broncoaspiração devido à sequela de paralisia cerebral, percebe-se que existe uma compreensão sobre alimentos que podem causar a aspiração do alimento e sobre o uso de espessante para atenuar este problema.

De acordo com Marques e Sá (2016), pais de crianças com PC alegam que o seu filho se engasga e perde alimento durante as refeições, e que ao analisar esta problemática, constatou-se que, muitas vezes, a posição empregada para dar a alimentação era muito inadequada, a comida muito liquidificada, a colher grande para a criança e introduzida na boca de forma incorreta. Para os autores supracitados, a elevação do encosto da cadeira no momento da refeição é fundamental para uma boa alimentação, assim como a consistência dos alimentos deve ser adaptada às limitações e necessidades da criança, de forma a minimizar o risco de aspiração de alimento. Os autores indicam o uso de espessante, que permitirá aos pais dar água, sopa ou frutas passadas aos seus filhos, minimizando o risco de engasgamento ou aspiração de comida. Estes autores afirmam que a aspiração do alimento pode causar sérios problemas como pneumonia, asfixia e mesmo a morte.

\title{
Como lidar com a criança com disfunções por PC
}

Pelo tema, pode-se identificar que esta categoria expressa mais diretamente demandas dos participantes, a partir do momento que remete a dúvidas sobre a abordagem à criança.

\begin{abstract}
Eu também tenho uma, ela com 4 anos de idade sofreu um semi-afogamento teve hipóxia, convulsionou. Aí ela ficou com a parte motora comprometida, ficou um tempo na AACD, depois saiu aí a gente encaminhou para a fisioterapia e para fono também, ela só fala "tia". Por que aprendeu na escola, aí agora eu tenho colocado ela com outra criança e aí eu sigo a fonetização e ela já tá pronunciando. Então quer dizer com estimulo ela vai desenvolver, mas a família é totalmente a parte né? O que a gente tá precisando é o comprometimento desses pais com 0 cuidar desses filhos e a disponibilização. (P2)
\end{abstract}

Eu tenho uma aluna que fica toda torta, eu devo ajeitar ela ou não? Ela tem PC grave e eu tenho medo de ajeitar ela. (P14)

A gente quanto professor é muito complicado posicionar o aluno. (P15) 
http://dx.doi.org/10.5902/1984686X42569

Nos discursos apresentados, percebe-se que os participantes se sentem despreparados para organizar a postura do aluno, seja por medo ou inexperiência, o que, consequentemente, agrava a alteração musculoesquelética. A criança com diagnóstico de paralisia cerebral necessita de suporte para controle postural e de membros superiores, visto que uma postura sentada adequada pode favorecer atividades como alimentação, respiração, comunicação, socialização e aprendizado (CAMPOS, 2013). Em contraposição, a falta de controle postural pode facilitar a luxação ou subluxação do quadril, que são complicações frequentes em pacientes com PC espástica sem prognóstico de marcha (JUNIOR; COLOMBO; ARISAWA, 2008). Isso indica também que o posicionamento inadequado pode ter consequências negativas, o que aponta para uma demanda de formação na clínica na biomecânica dos quadros de PC.

De acordo com Melo e Martins (2004), sentimentos como medo, insegurança e pena, entre outros, são manifestados de modo recorrente, pelos membros da escola regular diante da inclusão do aluno com deficiência, uma vez que, de modo geral, existe desconhecimento e também ideias preconcebidas em relação à deficiência e às pessoas que a apresentam.

\begin{abstract}
Meu aluno tem dificuldade motora expressiva na grafia, até que ponto era melhor que ele desenvolvesse uma maior habilidade para fazer uso da tecnologia, por exemplo, do uso do teclado a grafia, porque hoje até a nível de vestibular aceitam a adaptação. Eu comparo muito com professor de classe regular, ele fica insistindo que o menino faça aquele cabeçalho e o menino tá lá, desatento, fazendo nenhum sentido para ele, o professor as vezes passa 1 hora, 1 hora e $30 \mathrm{com}$ aquela atividade de cópia que o menino pode ter muito mais ganho. Até que ponto, ele sustentar o lápis para ele que tem dificuldade motora vai ajudar? (P13)
\end{abstract}

Crianças com comprometimento motor, na sala de aula, em sua maioria, deixam de participar de atividades devido a suas limitações motoras. Os educadores, devido a desconhecimento teórico ou por inexperiência prática, costumam repetir modelos e elaborar ações pedagógicas que não colaboram para o processo de inclusão de crianças com deficiência. Diante disso, o aspecto motor acaba por se justapor ao possível potencial cognitivo, que muitas vezes não é propriamente estimulado, ficando a criança apenas por ocupar um espaço cativo na sala de aula (FRANCO; GUERRA; CARVALHO, 2015).

Conforme Franco, Guerra e Carvalho (2015, p.92), o aspecto motor é central para a percepção dos educadores em relação aos limites e as possibilidades de desempenho acadêmico das crianças e, assim, eles se preocupam com o desempenho grafomotor. A habilidade motora para colocar no papel as letras do alfabeto norteia a ideia de escrita 
expressa pelos educadores. Desse modo, "como os demais colegas de sala, a criança PC deveria aprender a ler e a escrever treinando a escrita motora".

Ainda de acordo com os autores supracitados, mesmo dissonante de fundamentos que orientam a prática pedagógica, a crença de que o treino motor pode garantir o desenvolvimento da capacidade de escrita é evidenciada por educadores. É necessária a interlocução entre as equipes de reabilitação e pedagógica, numa relação que envolve teoria e o contexto da prática, o que possibilita a construção de novos olhares para com as crianças, seus limites e seus potenciais, e a sua participação no ambiente escolar. A equipe de reabilitação através desse contato torna possível compreender, mesmo que minimamente, o universo escolar, o fazer pedagógico. O distanciamento entre as duas áreas restringe as possíveis melhorias no tocante à inclusão de crianças com paralisia cerebral (FRANCO et al., 2015).

Neste sentido, uma das possibilidades de facilitar a inclusão é a introdução da Tecnologia Assistiva, que consiste em recursos e serviços que contribuem para promover ou ampliar habilidades de pessoas com limitações funcionais, motoras, sensoriais ou mentais e, dessa forma, promover a independência e a inclusão (MARINS; EMMEL, 2011).

\section{Outras patologias}

As falas, apresentadas em seguida, revelam que alguns profissionais confundem termos relacionados à saúde, o que pode trazer compreensão incoerente para com as especificidades de diferentes doenças, transtornos e incapacidades.

\footnotetext{
Existe autismo hipotônico? Ouvi em uma palestra que o autista era hipotônico porque não tinha vontade própria de mexer no objeto. (P4)

É uma espasticidade mental, por que tem uma rigidez mental (autista). (P5)

Eu tenho uma aluna com autismo que possui movimentos involuntários na cabeça (balança a cabeça) será que ela não tem nada relacionado? (P18)
}

A relação entre estes termos, característicos de disfunções neuromotoras, e a clínica do transtorno do espectro do autismo, não tem respaldo na literatura da área, o que demonstra falta de conhecimento sobre o tema elencado.

Ainda se observa nos educadores e também em profissionais da saúde que existe um desconhecimento sobre o real potencial de crianças, jovens e adultos que apresentam determinado tipo de deficiência. São muitos os alunos que necessitam do uso desses recursos e de professores e profissionais da área da saúde que necessitam de formação 
http://dx.doi.org/10.5902/1984686X42569

nessa área. Sendo assim, não se deve pensar isoladamente na capacitação do professor especializado. Ao contrário, é preciso considerá-la como parte integrante da formação, tanto dos profissionais da educação em geral, como também das áreas da saúde. Entretanto, sabe-se que ainda são poucas as Instituições de Ensino Superior que oferecem nos seus currículos disciplinas que abordem temas relacionados à Educação Especial. Estes fatores destacados acima levam a minimização da inclusão desses sujeitos que, muitas vezes, estão em sala de aula, porém alheios ao processo de aprendizagem porque não apresentam fala ou escrita funcional (SCHIRMER; WALTER; NUNES, 2011).

\section{Dificuldades e demandas}

A partir dos dados analisados, foram identificadas as dificuldades dos participantes, 0 que direciona para as demandas dos mesmos, apresentados no quadro abaixo:

Quadro 1 - Descrição das dificuldades dos profissionais do AEE. Recife, 2017

\begin{tabular}{|c|c|}
\hline \multirow{3}{*}{ Terapias } & $\begin{array}{l}\text { Dificuldades em encaminhar alunos com comprometimento grave, } \\
\text { principalmente adolescentes, devido a lotação dos serviços e idade dos } \\
\text { alunos. }\end{array}$ \\
\hline & $\begin{array}{l}\text { Desconhecimento sobre locais para encaminhamento de serviços de } \\
\text { reabilitação. }\end{array}$ \\
\hline & $\begin{array}{l}\text { Dificuldades em obter ou compreender laudos de profissionais da saúde, } \\
\text { bem como falta de especificidade nos laudos. }\end{array}$ \\
\hline \multirow{5}{*}{$\begin{array}{c}\text { Solicitações } \\
\text { dos } \\
\text { profissionais } \\
\text { do AEE }\end{array}$} & $\begin{array}{l}\text { Despreparo para lidar com manuseios dos alunos com sequelas de } \\
\text { Paralisa Cerebral. }\end{array}$ \\
\hline & $\begin{array}{l}\text { Ausência e indisponibilidade dos pais dos estudantes com deficiência no } \\
\text { ambiente escolar. }\end{array}$ \\
\hline & $\begin{array}{l}\text { Falta de conhecimento dos profissionais com as patologias e confusão de } \\
\text { conceitos. }\end{array}$ \\
\hline & $\begin{array}{l}\text { Falta de acesso do aluno a procedimentos que podem facilitar sua } \\
\text { funcionalidade, como o uso de toxina botulínica. }\end{array}$ \\
\hline & $\begin{array}{l}\text { Limitação na prescrição e construção de dispositivos assistivos para } \\
\text { suporte a tarefas escolares, dentre eles adaptações de lápis. }\end{array}$ \\
\hline
\end{tabular}

Fonte: Elaboração dos autores (2020).

A partir das demandas levantadas, é notado que existem obstáculos no que se refere aos locais de tratamento para adolescentes, e a angústia desses profissionais na busca de auxílio para os alunos. 
No que se refere aos procedimentos de saúde, preconiza-se uma intervenção o mais precoce possível, pois a longa espera para iniciar a reabilitação pode comprometer a qualidade da recuperação do paciente, como o estabelecimento de sequelas permanentes que comprometam a qualidade de vida. Deste modo, é pertinente investir em estratégias, como aumento de profissionais e ampliação do espaço físico, consequentemente aumentar a capacidade de atendimento, para continuar a diminuir esse tempo de espera, que servirá como precursor do serviço para análises futuras (SILVA et al., 2016).

Segundo a Secretaria de Saúde do Recife (RECIFE, 2014), o Recife possui 9 núcleos de reabilitação física concedidos pelo Sistema Único de Saúde (SUS), além de Organizações não governamentais (ONGs).

Ainda assim, foi identificada a falta de acesso de estudantes a atendimentos na saúde, seja atendimento médico ou de saúde funcional/reabilitação, assim como o longo tempo de espera para receber tais atendimentos (NUNES et al., 2014). A respeito da organização, os gestores do SUS convivem com a indisponibilidade de profissionais o que reflete na superlotação dos serviços de saúde, gerando longas filas de espera, bem como a falta de protocolos de organização dos serviços (MORAES, 2017). Com os educadores, o objetivo deve ser direcionado ao aparecimento das dificuldades relacionais decorrentes de conteúdos afetivos e das emoções desencadeadas pela presença de pessoas com deficiências, em explicitar as potencialidades e necessidades desses estudantes e em apoiar as atividades coletivas, envolvendo a todos. Como ações, o terapeuta ocupacional propõe reuniões com os educadores para a discussão de temas relativos à presença do estudante com deficiência no contexto escolar através de oficinas, de palestras, entre outras possibilidades de construção de diálogos e trocas. Além de ser facilitador na tríade escola-aluno-família, para apoiar a inclusão de todas as crianças, bem como integrar a equipe escolar para desenvolvimento de ações junto ao professor com o objetivo de superar barreiras para a inclusão (FIORINI; ARAÚJO, 2015).

\section{Conclusão}

Diante do exposto, observa-se a preocupação dos profissionais do Atendimento Educacional Especializado para com a compreensão das facilidades e limitações dos alunos com sequela de Paralisia Cerebral; a presença de crenças populares sobre o tratamento da icterícia; a utilização de termos inadequados em relação às características dos quadros clínicos; medo de realizar procedimentos para a alimentação de crianças com 
http://dx.doi.org/10.5902/1984686X42569

maior comprometimento motor pelo risco de vida; bem como os manuseios destas crianças, o que dificulta os cuidados básicos, o posicionamento adequado e o desempenho funcional das mesmas no ambiente escolar, no qual passam um período de tempo significativo do dia.

Os resultados indicam o desconhecimento e a insegurança dos profissionais do $A E E$ em lidar com esta população, o que aponta para a necessidade de realização de parcerias entre a saúde e a educação na política de formação, indispensável para a melhoria da qualidade de vida dos alunos com deficiência e dos profissionais envolvidos.

Esta pesquisa levantou demandas sobre a parceria com a rede de saúde, que é indispensável como apoio ao trabalho dos profissionais de $\mathrm{AEE}$, pois estes referiram que muitos alunos não são assistidos por equipes de reabilitação, seja por ausência de vagas nos serviços, seja pelo envolvimento afetivo. A fragilidade da interação com a rede de saúde também foi percebida a partir do desconhecimento dos mesmos quanto à existência e porta de entrada dos serviços disponíveis para a realização de encaminhamentos.

Sugere-se que sejam desenvolvidos estudos futuros e ações na rede escolar, junto ao desenvolvimento da política de formação na educação inclusiva, com o aprofundamento teórico e prático dos temas abordados nesta pesquisa, assim como com outros transtornos e incapacidades, a partir da identificação da população com deficiência incluída na rede, contribuindo com o trabalho da equipe envolvida e com o desenvolvimento dos alunos.

\section{Referências}

ALVES, Heliana C.; TEBET, Gabriela G. de C. A formação de professores no paradigma da inclusão: a educação infantil e a educação especial em pauta. Cadernos de Terapia Ocupacional da UFSCar, São Carlos, v. 17, n. 1, p. 7-23, 2009.

BRASIL. Lei de Diretrizes e Bases da Educação Nacional. Lei n. 9.394 de 20 de dezembro de 1996. Estabelece as diretrizes e bases da educação nacional. Diário Oficial [da República Federativa do Brasil], Brasília, DF, 1996.

BRASIL. Ministério da Educação. Resolução CNE/CEB n. 4, de 2 de outubro de 2009. Institui Diretrizes Operacionais para o Atendimento Educacional Especializado na Educação Básica, modalidade Educação Especial. Conselho Nacional de Educação. Brasília, 2009.

BRASIL. Ministério da Educação. Marcos Político-Legais da Educação Especial na Perspectiva da Educação Inclusiva. Secretaria de Educação Especial. Brasília, 2010. 
http://dx.doi.org/10.5902/1984686X42569

BRASIL. Ministério da Saúde. Diretrizes de Atenção à Pessoa com Paralisia Cerebral. Secretaria de Atenção à Saúde. Brasília, 2013.

BRASIL. Lei no $\mathbf{1 3 . 1 4 6}$ de 6 de julho de 2015. Dispõe sobre a Lei Brasileira de Inclusão da Pessoa com Deficiência. Diário Oficial [da República Federativa do Brasil], Brasília, DF, 2015.

BRASIL. Constituição da República Federativa do Brasil de 1988. Brasília, DF: Presidência da República, [2016]. Disponível em:

http://www.planalto.gov.br/ccivil_03/Constituicao/Constituicao.htm. Acesso em: 25 mai. 2017.

CAMPOS, Maria Alice Alvarenga Duarte. Cadeira de rodas e acessórios para adequação postural na paralisia cerebral: uma análise documental. Cadernos de Terapia

Ocupacional da UFSCar, São Carlos, v. 21, n. 1, p. 43-49, 2013.

CAREGNATO, Rita Catalina Aquino; MUTTI, Regina. Pesquisa qualitativa: análise de discurso versus análise de conteúdo. Texto \& Contexto - Enfermagem, Florianópolis, v. 15, n. 4, p. 679-684, 2006.

CHAGAS, Paula Silva de Carvalho. et al. Classificação da função motora e do desempenho funcional de crianças com paralisia cerebral. Revista Brasileira de Fisioterapia, São Carlos, v. 12, n. 5, p. 409-416, 2008.

DIAS, Caroline Pieta. et al. Paralisia cerebral em pediatria. Pediatria Moderna, São Paulo, v. 51, n. 6, p. 224-229, 2015.

FIORINI, Bianca Sampaio; ARAÚJO, Rita de Cássia Tibério. Apoio de Terapia Ocupacional para a participação escolar de criança com artrogripose múltipla congênita: um estudo de caso. Revista Educação Especial, Santa Maria, v. 28, n. 51, p. 209-224, 2015.

FRANCO, Marco Antonio Melo; GUERRA, Leonor Bezerra. O ensino e a aprendizagem da criança com paralisia cerebral: ações pedagógicas possíveis no processo de alfabetização. Revista Educação Especial, Santa Maria, v. 28, n. 52, p. 311-324, 2015.

FRANCO, Marco Antonio Melo; GUERRA, Leonor Bezerra; CARVALHO, Alysson Massote. Discursos, interlocuções e prática pedagógica no ensino da criança com paralisia cerebral. Educação em Foco, Belo Horizonte, v. 18, v. 25, p. 77-98, 2015.

FREIRE, Paulo. Educação como prática da liberdade. Rio de Janeiro: Paz e Terra, 1967.

JUNIOR, Gerson Quadros; COLOMBO, Alessandra Cristina da Silva; ARISAWA, Emília Angela Loschiavo. Importância do ortostatismo em crianças com paralisia cerebral. In: VIII ENCONTRO LATINO AMERICANO DE INICIAÇÃO CIENTÍFICA E IV ENCONTRO LATINO AMERICANO DE PÓS GRADUAÇÃO - Universidade do Vale do Paraíba, 2008, São José dos Campos. Disponível em: http://www.inicepg.univap.br/cd/INIC_2004/trabalhos/inic/pdf/IC4-2.pdf. Acesso em 25 mai. 2017. 
LUCHESI, Bruna Moretti; BERETTA, Maria Isabel Ruiz; DUPAS Giselle. Conhecimento e uso de tratamentos alternativos para icterícia neonatal. Cogitare Enfermagem, São Paulo, v. 15, n. 3, p. 506-12, 2010.

MANCINI, Marisa Cotta; et al. Gravidade da paralisia cerebral e desempenho funcional. Revista Brasileira de Fisioterapia, São Carlos, v. 8, n. 3, p. 253-260, 2004.

MARINS, Simone Cristina Fanhani; EMMEL, Maria Luisa G. Formação do terapeuta ocupacional: acessibilidade e tecnologias. Cadernos de Terapia Ocupacional da UFSCar, São Carlos, v. 19, n. 1, p. 37-52, 2011.

MARQUES, Joana Mendes; SÁ, Luís Octávio. A alimentação da criança com paralisia cerebral: dificuldades dos pais. Revista de Enfermagem Referência, Coimbra, v. 4, n. 11, p. 11-19, 2016.

MELO, Francisco Ricardo Lins Vieira de; MARTINS, Lúcia de Araújo Ramos. O que pensa a comunidade escolar sobre o aluno com Paralisia Cerebral. Revista Brasileira de Educação Especial, Marília, v. 10, n. 1, p. 75-92, 2004.

MORGAN, Catherine. et al. Optimising motor learning in infants at high risk of cerebral palsy: a pilot study. BMC Pediatrics, London, v. 15, n. 30, p. 114-129, 2015.

MORAES, Rianna Carvalho. De que SUS estamos falando? Um olhar sobre as percepções da mídia impressa do Distrito Federal, no ano de 2016. 2017. Trabalho de Conclusão de Curso (Bacharel em Saúde Coletiva) - Universidade de Brasília, Brasília, 2017.

NUNES, Bruno Pereira. et al. Desigualdades socioeconômicas no acesso e qualidade da atenção nos serviços de saúde. Revista de Saúde Pública, São Paulo, v. 48, n. 6, p. 968-976, 2014.

PERAZZO, Ângela Lanziotti. Terapia ocupacional. In PERAZZO, Ângela Lanziotti; RIZO, L. R., SANTOS, L. S. B., MARQUES, Valéria de Cássia (Org.), Reabilitação - Med. Física Reabil. - AACD. São Paulo: Manole, 2015, p. 873-894.

RECIFE. Governo Municipal. Secretaria de Saúde do Recife. Secretaria Executiva de Coordenação Geral, Gerência Geral de Planejamento. Plano municipal de saúde 20142017. Secretaria de Saúde do Recife, 2014.

RECIFE. Secretaria de Educação. Política de ensino da rede municipal do Recife. Educação inclusiva: múltiplos olhares. Secretaria de Educação, 2015.

SCHIRMER, Carolina Rizotto; WALTER, Cátia Crivelenti de Figueiredo; NUNES, Leila Regina d'Oliveira de Paula. A tecnologia assistiva na prática de formação inicial de futuros professores da escola inclusiva. In: Anais do X ENCONTRO DE PESQUISA EM

EDUCAÇÃO DA REGIÃO SUDESTE, 2011, Rio de Janeiro. Disponível em: http://www.lateca-uerj.net/publicacoes/docs/Schirmer_Walter\%20e\%20Nunes.pdf. Acesso em 25 mai. 2017. 
SILVA, Jéssica Carolina Gomes da. et al. Caracterização do serviço de terapia ocupacional em um centro de reabilitação e medicina física. Revista de Enfermagem UFPE On Line, Recife, v. 10, n. 11, p. 3848-58, 2016.

SPOSITO, Maria Matilde de Mello. Cirurgias e intervenções físicas no tratamento da espasticidade na paralisia cerebral. Acta Fisiátrica, São Paulo, v. 17, n. 2, p. 84-91, 2010.

TAVARES, Lídia Mara Ferdandes Lopes; SANTOS, Larissa Medeiros Marinho dos; FREITAS, Maria Nivalda Carvalho. A Educação Inclusiva: um Estudo sobre a Formação Docente. Revista Brasileira de Educação Especial, Marília, v. 22, n. 4, p. 527-542, 2016.

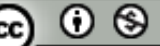

This work is licensed under a Creative Commons Attribution-NonCommercial 4.0 International (CC BY-NC 4.0) 